\title{
Establishing a National Standard Method for Operational Mixing Height Determination
}

\author{
MATTHEW G. FEARON and TIMOTHY J. BROWN \\ Desert Research Institute, Reno, Nevada \\ GARY M. CURCIO \\ IPA Fire Environment Specialist, LLC, La Grange, North Carolina
}

(Manuscript received 9 April 2015; review completed 2 September 2015)

\begin{abstract}
Since the 1960s the Holzworth method has remained a primary tool for operational mixed-layer height determination. The air volume through which ground-based pollutants vertically disperse defines the mixed layer. The appeal of this method rests on the simple mechanics of making a forecast where knowledge of the surface air temperature in concert with the background vertical structure is sufficient. The National Weather Service routinely issues forecasts using this method for air-quality and wildland fire activities.

Methods of this type that are based principally on the static stability structure of the atmosphere and exclude vapor content or dynamical processes (e.g., advection and wind shear) can misrepresent the mixing height calculation. Systematic errors, such as the height being too low or high, can complicate wildland fire activities (e.g., go/no-go burn decisions). Motivation for the present study emerges from this premise, and thus examines the mixing height computed from four methods.

Mixing height methods employed in this study include Holzworth, Stull, bulk Richardson number, and turbulent kinetic energy - where the latter two include dynamical processes. Mixing height also was derived from satellite-based lidar data to provide an observed proxy and validation. Results from a method intercomparison show that turbulent kinetic energy is the most robust and well suited as a national standard method for operational use - having both thermodynamic and dynamic processes incorporated. The bulk Richardson number and Stull methods are other possibilities because their calculations are not model dependent and heights are consistent with those from turbulent kinetic energy.
\end{abstract}

\section{Introduction}

Smoke from wildfire and prescribed burning in the United States is important in terms of human health as well as environmental and transportation safety (Moeltner et al. 2013). Local dispersion is a major concern for many wildland fire and air-quality agencies that participate in wildfire and prescribed fire activities [e.g., United States and State Forest Services, Bureau of Land Management, National Weather Service Forecast Offices (NWSFOs), and state and local air-quality agencies]. Prediction of smoke dispersion indices (including mixing height ${ }^{1}$, transport wind speed, and venti-

\footnotetext{
1 Mixing height and mixed-layer height are synonymous terms in this paper. Mixing depth and mixed-layer depth also are synonymous and define the air volume between the ground and the mixing height.
}

lation index) is a part of operational fire weather forecasts issued by NWSFOs. For the past several years, the user community (e.g., local and state land managers, foresters, and personnel from the aforementioned agencies) has expressed concern over the accuracy of methods used to compute mixing height across NWSFOs (National Wildfire Coordinating Group 2012-2015, personal communication), in particular the widely used Holzworth method (Holzworth 1964, 1967). Local or regional discrepancies in the mixing height calculation also arise when the Holzworth method is used in a nonstandard fashion across NWSFOs. Inconsistency in the method complicates wildland fire go/no-go burn decisions and jeopardizes wildfire impact assessments. The current study revisits the Holzworth technique and three documented alternatives for mixing height determination-namely, the

Corresponding author address: Matthew G. Fearon, 2215 Raggio Parkway, Reno, NV 89512

E-mail: matthew.fearon@dri.edu 
Stull, bulk Richardson number (RI), and turbulent kinetic energy (TKE) methods - in order to determine which method is the most robust and appropriate as a national standard.

Seibert et al. (2000) defined the mixing height as an upper boundary or lid in the atmosphere to which ground-level pollutants vertically disperse. The development of the mixed layer is a function of turbulence that can arise from solar-induced thermal gradients (the convection process), and/or mechanical stirring from wind shear or advection. NWSFOs issue routine fire weather forecasts that include mixing height based primarily on the Holzworth method (see Table 1). This procedure follows the adiabatic principle of parcel theory and static stability where mixed-layer height is traced to the altitude and intersection of the hypothetical surface parcel with its environment, as shown in Fig. 1 with the potential temperature ${ }^{2}(\theta)$ profile.

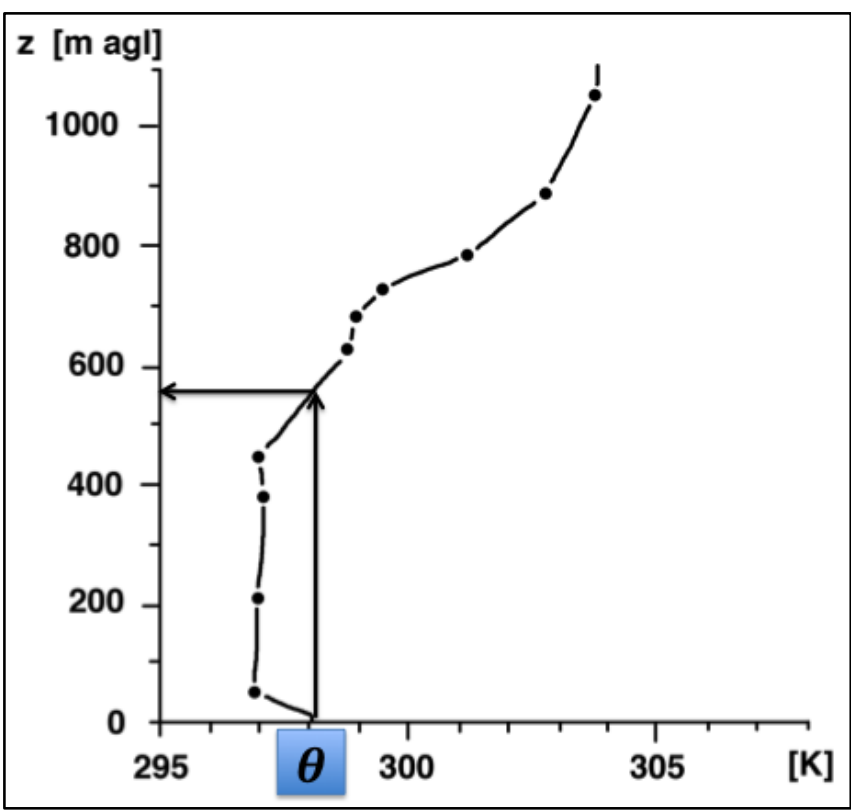

Figure 1. Illustration of surface parcel displacement (vertical arrow) for potential temperature ( $\theta$, dry atmospheric assumption) associated with the Holzworth method. The horizontal arrow denotes the mixing height location. Click image for an external version; this applies to all figures hereafter.

The Holzworth technique provides a quick and reasonable estimate of mixing height from temperature profile data (soundings and/or model-derived soundings). However, the use of $\theta$ (i.e., a dry atmosphere as-

2 The potential temperature is inclusive of dry air only, synonymous with the term dry potential temperature. sumption) leads to consistent height underestimation (as shown later in section 4). The neglect of moisture, regardless of the environment (e.g., high desert, moist continental, or coastal), misrepresents the density of the surface parcel and yields a lower mixing height estimate (Fearon 2000). Figure 2 is a graphical depiction of a dry versus moist (unsaturated) atmosphere and includes the use of the virtual potential temperature ${ }^{3}\left(\theta_{v}\right)$. Examining the static stability of the atmosphere with $\theta_{v}$ follows the mixing height method described by Stull (1991).

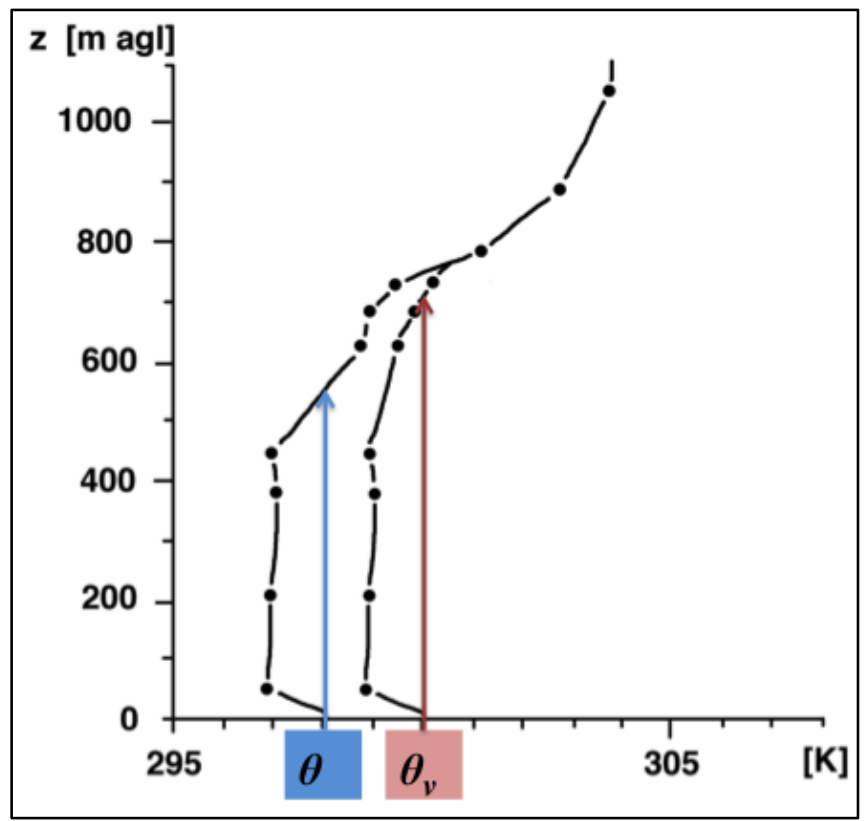

Figure 2. Dry versus moist (unsaturated) atmosphere via $\theta$ (blue) and $\theta_{v}$ (red), respectively. Note the impact on the surface parcel displacement and the difference between dry and moist (unsaturated) values.

For this study, mixing heights were computed from the two most commonly used operational methods (namely, Holzworth and Stull ${ }^{4}$ ). Heights from RI and the vertical decline of TKE also were computed and compared. RI is the ratio of the buoyancy to wind shear and TKE is a combined representation of buoyancy, wind shear, advection, and other gradients and

\footnotetext{
3 The virtual potential temperature is calculated in the same way as $\theta$ except $T$ is replaced by virtual temperature $\left(T_{v}\right)$, the temperature that dry air would have if its pressure and density were equal to those of a given sample of moist (unsaturated) air [glossary. ametsoc.org/wiki/Virtual_potential_temperature].

4 Operational use of Stull over Holzworth by some agencies in moist environments is not uncommon (National Wildfire Coordinating Group discussions 2012-2015, personal communication).
} 
Table 1. Survey of the mixing height methods used (as a first look) by two randomly chosen NWSFOs within each of the six regions.

\begin{tabular}{|c|c|c|c|c|}
\hline Region & Forecast Office & Identifier & Method Used & Office Telephone \\
\hline Pacific & Guam & GUM & Not sure of method & $671-472-0900$ \\
\hline Pacific & Hawaii & HFO & Not sure of method* & $808-973-5286$ \\
\hline Western & Missoula & MSO & Holzworth & $406-329-4840$ \\
\hline Western & Sacramento & STO & Holzworth & $916-979-3051$ \\
\hline Eastern & Greenville & GSP & Holzworth & $864-848-3859$ \\
\hline Eastern & State College & CTP & Holzworth & $814-231-2408$ \\
\hline Central & Duluth & DLH & Holzworth & $218-729-6697$ \\
\hline Central & Jackson & JKL & Holzworth & $606-666-8000$ \\
\hline Southern & Birmingham & BMX & Holzworth & $205-664-3010$ \\
\hline Southern & Little Rock & LZK & Holzworth* & $501-834-0308$ \\
\hline Alaska & Fairbanks & AFG & Holzworth & $907-271-5088 / 907-458-3700$ \\
\hline Alaska & Anchorage & AFC & Holzworth & $907-271-5088 / 907-266-5105$ \\
\hline
\end{tabular}

\footnotetext{
* Not satisfied with grid data provided.

${ }^{\text {a }}$ High moisture content and inversions not reflected in grids.

b Currently evaluating Stull versus Holzworth methods.

c Current method under discussion.
}

perturbation terms that quantify the kinetic energy throughout the atmospheric column. RI and TKE each provide a combined measure of the static and dynamic stability whereas Holzworth and Stull provide an estimate of the static stability only. RI and TKE are well documented in the literature (e.g., Vogelezang and Holtslag 1996; Seibert et al. 1997; Zilitinkevich and Baklanov 2002; Jeričević and Grisogono 2006; Lee et al. 2008; Kiefer et al. 2015). Use of TKE for mixing height determination is less common since computation requires finely resolved, evenly spaced data (vertically and horizontally), such as from a numerical model. Mixing heights from these four methods (Holzworth, Stull, RI, and TKE) also were compared to those derived from satellite-based lidar where the latter were chosen to represent observed data and provide an independent measure. The spatial and temporal resolution of the lidar data provided a large coincident sample size against model grid points (discussed in section 3).

Section 2 of this paper begins with a brief background into the origin of air-pollution control in the United States and related research, including mention of the classic mixed-layer model and boundary layer concepts used in this study. Section 3 describes the relevant data, the four mixing height methods of interest - Holzworth, Stull, RI, and TKE — and the data analysis methods used. Section 4 provides a discussion of results from a mixing height method intercomparison. Examples of the vertical structure and spatial extent associated with mixing height discrepancies also are presented. Section 5 is reserved for a summary of results and recommendations from the authors on the most robust approach for mixing height determination.

\section{Background}

The origin of comprehensive air pollution control in the United States can be traced back to the midtwentieth century. The National Air Pollution Act of 1955 and the Clean Air Act of 1963 - and its subsequent amendments in 1970 (McCarthy 2005) - represent two such pieces of regulatory legislation. Both were enacted in response to human health concerns and the widespread increase of airborne contaminants from industrialization and mobile sources. Air-pollution research was one of the primary objectives outlined in this legislation - in particular investigation of urban emissions, dispersion, and transport in the context of human health impacts. One of the central research themes to emerge during the 1960s was the concept of monitoring and predicting the rate of atmospheric dispersion and transport of airborne contaminants.

During the mid- to late-twentieth century numerous studies were performed on atmospheric dispersion in the low-level atmosphere, or the volume of air designated as the mixed layer (e.g., Pasquill 1961; Holzworth 1964; Turner 1964; Tennekes 1973; Yamada and Berman 1979; Stull 1991). Ball (1960) was arguably the first to tackle the subject in the context of the Archimedes Principle, where the density differential between the hypothetical surface parcel and its 
surrounding environment increases when solar heating is introduced at the air-ground interface. In such circumstances, the static stability stratification of the air column changes with unstable air developing at the lower boundary and facilitating upward acceleration. As the heated air mixes upward, eventually the density differential in the air column becomes zero and the upward acceleration vanishes. Yet, the momentum gained on the upward journey carries air into the adjoining layer and simultaneously promotes downward motion (or entrainment) of upper-level air. The turbulent motion associated with the buoyancy and entrainment leads to a stratified state where the temperature decrease with height follows the adiabatic rate. Other atmospheric constituents (e.g., wind, water vapor, and pollution) that take part in the turbulent motion become uniform in this mixed layer. This process becomes increasingly complex in the presence of overlying clouds such as non-precipitating cumulus (as discussed by Lilly 1968 and Betts 1973).

Prognostic models of mixed-layer development serve as another common method of height estimation. Figure 3 illustrates the main sublayers of the mixedlayer model at the time of maximum heating. These include the shallow surface layer near the ground, the deep turbulent (free convection) layer, and the entrainment zone atop demarking the separation between the boundary layer and the free atmosphere. This depiction is representative of the mixed-layer (or jump) model described by Tennekes (1973), Tennekes and Driedonks (1981), Lewis (2007), and others, where the important changes in the $\theta$ are a function of the variation in the buoyancy flux $\left(\overline{w^{\prime} \theta^{\prime}}\right.$; prime denotes perturbation and overbar denotes mean) at the top and bottom boundaries via the sharp increase and decrease, respectively. The fundamental equation for this model is given by:

$$
\frac{\partial \bar{\theta}}{\partial t}=\left[\left(\overline{w^{\prime} \theta^{\prime}}\right)_{S}-\left(\overline{w^{\prime} \theta^{\prime}}\right)_{H}\right]\left[\frac{1}{H}\right]
$$

where $w$ is vertical velocity, $H$ is the top of the mixed layer, and $S$ is the surface. Models of this type that examine turbulent behavior over the entire depth of the boundary layer are identified as nonlocal schemes. Alternatively, attempts to quantify turbulent behavior and static stability via localized gradients are identified as local schemes. The latter methods often are inconsistent with observations, as most of the turbulent energy is associated with the largest eddies, which typically have influence over the full depth of the

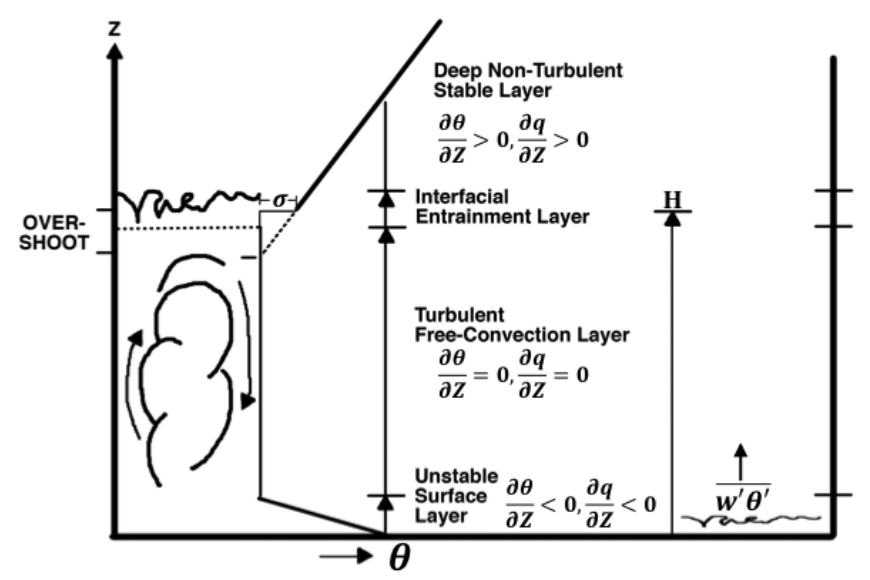

Figure 3. Illustration adapted from Lewis (2007) of the classic mixed-layer model at the mature stage. Note the sharp decrease in $\theta$ and the upward acceleration arrow associated with the buoyancy flux $\left(\overline{w^{\prime} \theta^{\prime}}\right)$ in the surface layer, the uniform profile in the freeconvection layer, and the increase or jump $(\sigma)$ near the mixed-layer top $(\boldsymbol{H})$ associated with the entrainment layer.

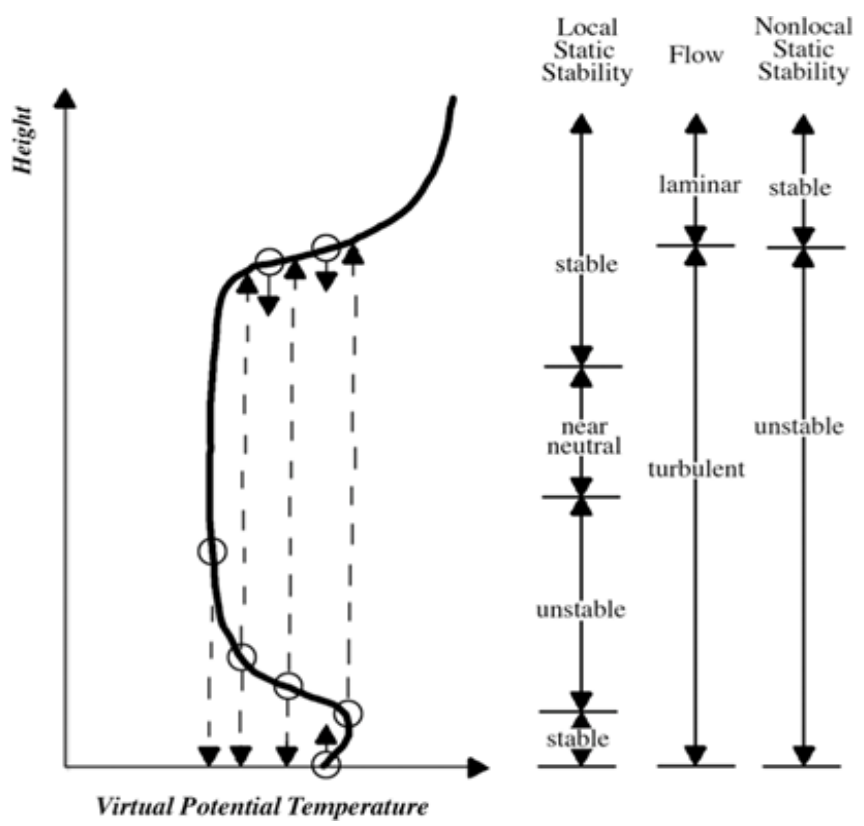

Figure 4. Depiction of parcel displacements associated with the Stull method via $\theta_{v}$, including local versus nonlocal static stability and flow type. Adapted from Stull (1991).

boundary layer (Stensrud 2007). Figure 4 illustrates nonlocal versus local static stability classification for an example sounding. Parcel displacements follow the nonlocal definition where static stability and flow type are evaluated over the entire atmospheric column. Assessment of the environmental profile and its vertical variation over discrete segments follows the local definition.

As described by Stensrud (2007), Eq. 1 and the concept of local versus nonlocal introduces the fun- 
damental problem associated with boundary layer predictive schemes - namely, turbulence closure. As in the previous mixed-layer model, instantaneous variables like $\theta$ and $w$ are expressed in terms of their mean and turbulent (perturbation) components (e.g., $\bar{\theta}$ and $\theta^{\prime}$ or $\bar{w}$ and $w^{\prime}$, respectively). And although the mean quantity, $\bar{\theta} / \partial t$, is the desired parameter, it remains a function of turbulent multiples or correlation terms like the buoyancy flux $\left(\overline{w^{\prime} \theta^{\prime}}\right)$. The appearance of the latter in the governing equation set introduces unknown variables that require parameterization (or approximation) where the principles of turbulence closure are utilized. A double correlation term like buoyancy flux would follow first-order turbulence closure. A triple correlation term (three turbulent multiples) would follow second-order closure, and so on, where the order follows the increase of turbulent multiples. As with static stability assessment, turbulence closure can be performed locally or non-locally. Nonlocal closure relates unknown variables to known variables at any number of other vertical grid points within the column. Local closure relates known variables to unknowns at nearby vertical grid points. The principles of closure gain in complexity with the addition of terms and order of moments sought. Refer to Stull (1988) for a more in-depth description of turbulence closure.

Numerical schemes that characterize the planetary boundary layer (PBL) utilize the principles of turbulence closure to obtain a closed set of prognostic equations for temperature, moisture, and momentum. These equations are then used to quantify TKE, a measure of the intensity of turbulence. Descriptively, the tendency for TKE to increase or decrease is given by:

$$
\frac{\Delta T K E}{\Delta t}=A+S h+B+T r-\varepsilon
$$

where $A$ is the advection of TKE by the mean wind, $S h$ is the shear generation, $B$ is the buoyant production or consumption, $\operatorname{Tr}$ is transport by turbulence motions and pressure gradients, and $\varepsilon$ is the viscous dissipation rate. Each of the former terms contributes to the generation or consumption of TKE where the intensity declines from the ground upward and dissipation typically identifies the top of the boundary layer.

Threshold values of TKE also are commonly used to determine mixed-layer height. The ratio of buoyancy to shear - the two most dominant terms in the TKE equation-defines the RI (Stull 2000). According to Richardson (1921), threshold values of RI can be used to categorize flow type. Values $\geq 1$ signify laminar flow, while those $<1$ suggest turbulent flow. Richardson (1921) identified a critical value of 0.25 to indicate when turbulent flow is certain. However, since Richardson's work, certain threshold values of RI between 0.25 and 1.0 have been found to be consistent with the TKE dissipation in the boundary layer and the mixed-layer height. For example, a TKE of 0.505 is a threshold used in the operational North American Mesoscale (NAM) Forecast System (Janjić 2001; Lee et al. 2008).

\section{Methods and data}

For this study, afternoon mixing heights were computed using the Holzworth, Stull, RI, and TKE for a two-year period (2009-2010) over the contiguous United States. Source data for height calculations included hourly numerical model soundings and postprocessed profiles of aerosol extinction, as measured by satellite-based lidar. Mixing height methods, their source data, and the analysis methods used are described in the following subsections.

\section{a. Holzworth and Stull mixing height methods}

Both the Holzworth and Stull methods rely on the principles of static stability and parcel theory. The primary difference between the methods is the source variable, $\theta$ versus $\theta_{v}$, where the inclusion of moisture in the latter can yield a value greater than the former by as much as $3^{\circ} \mathrm{C}$ (Fearon 2000). This difference in the environmental profile with height, particularly near the surface, impacts the buoyancy assessment of the surface parcel and the mixing height calculation (see Fig. 2). The mixing height from both methods is found at the altitude at which the upward vertical displacement or the positive buoyancy of the surface parcel terminates (also the parcel's intersection with the environmental profile). Parcel displacement(s) for the Holzworth and Stull methods are depicted in Figs. 1 and 4, respectively. Parcel displacements beyond that of the surface parcel for the Stull method (Fig. 4) provide further detail on the static stability, particularly the depth of instability and the associated flow type. As depicted, the depth of instability is not necessarily consistent with the positive buoyancy of the surface parcel. In such cases, low-level stable air may become well mixed in response to daytime heating or dynamical forcing (see Figs. 4 and 5). Following either outcome, the surface buoyancy would become consistent among the methods with differences again tied exclusively to the source variable (see Fig. 2). 




Figure 5. Same as Fig. 4 except the low-level inversion has now mixed out. Local and nonlocal static stability now are equivalent.

\section{b. TKE and RI mixing height methods}

Profiles of TKE and its decline with height were examined from model output (data described below) where a threshold value of $0.1 \mathrm{~J} \mathrm{~kg}^{-1}$ is used to identify the mixed-layer height (Fig. 6, left panel). As discussed in Holtslag and Moeng (1991), eddy diffusivity calculations of heat and transport reveal that the value of 0.1 corresponds consistently with boundary layer inversion height. Lee et al. (2008) also described the use of this threshold for TKE in relation to RI for planetary boundary layer height determination within the operational NAM.

RI represents the ratio of the buoyancy flux and wind shear terms of the TKE equation. In bulk form, the equation takes the form of:

$$
R I=\frac{\left(g / \overline{\theta_{v}}\right) \Delta \overline{\theta_{v}} \Delta Z}{\left[(\Delta \bar{U})^{2}+(\Delta \bar{V})^{2}\right]}
$$

where $g$ is gravity, $Z$ is height, $U$ is the $x$ component of the wind, $V$ is the $y$ component of the wind, the numerator represents the buoyancy (also the BruntVäisälä frequency) as the vertical change in the mean $\theta_{v}$ across the layer, and the denominator is the vertical variation of the horizontal wind. In this study, a height consistent with a threshold of 0.505 (unitless) from RI identified the mixed-layer height following a profile search from the ground upward (Janjić 2001; Lee et al.

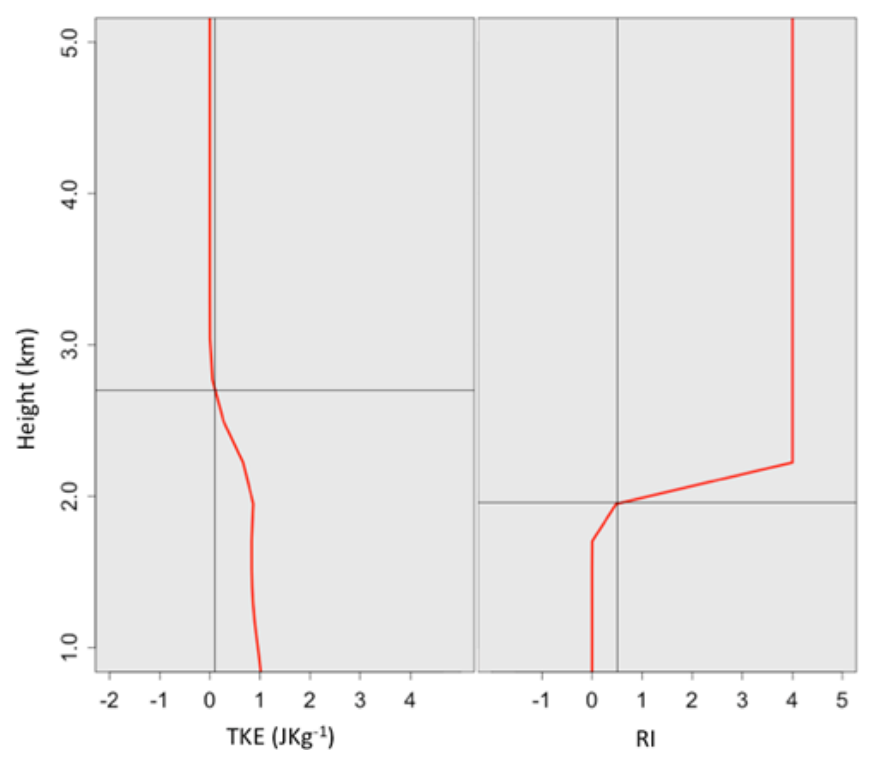

Figure 6. Illustration of the TKE (left) and RI (right) mixing height method mechanics. The thin gray vertical lines depict the threshold limits of $0.1 \mathrm{~J} \mathrm{~kg}^{-1}$ (left) and 0.505 (right). The thin black horizontal lines depict mixing height location in relation to the threshold limits.

2008). An RI calculation that exceeds this value signifies a decline in turbulence (Fig. 6, right panel). Note that both TKE and RI include vapor content in their respective calculations.

\section{c. Rapid Update Cycle Version 2 (RUC2) analysis}

The RUC2 is a hydrostatic model with 40 isentropic-sigma hybrid model surfaces defining the vertical structure. Turbulent mixing, including the boundary layer, is prescribed explicitly using the methods of Burk and Thompson (1989), a nonlocal scheme with level-two closure (third-order moments are parameterized). Additional details on model physics can be found in Benjamin et al. (2004). In this study, RUC2 model analysis grids for the period 2009-2010 were used to generate mixing heights. The hourly frequency and horizontal grid spacing $(13 \mathrm{~km})$ provided collocation opportunities for the satellite-based lidar data (Fig. 7). Profiles of $\theta, \theta_{v}$, geopotential height, $U$, and $V$ from RUC2 grid cells were extracted and used to compute mixed-layer height for the Holzworth and Stull methods, along with RI. TKE profiles were also available and used to determine a mixing height.

\section{d. Lidar data}

Aerosol retrievals from the National Aeronautics and Space Administration (NASA) Cloud-Aerosol Lidar and Infrared Pathfinder Satellite Observation 


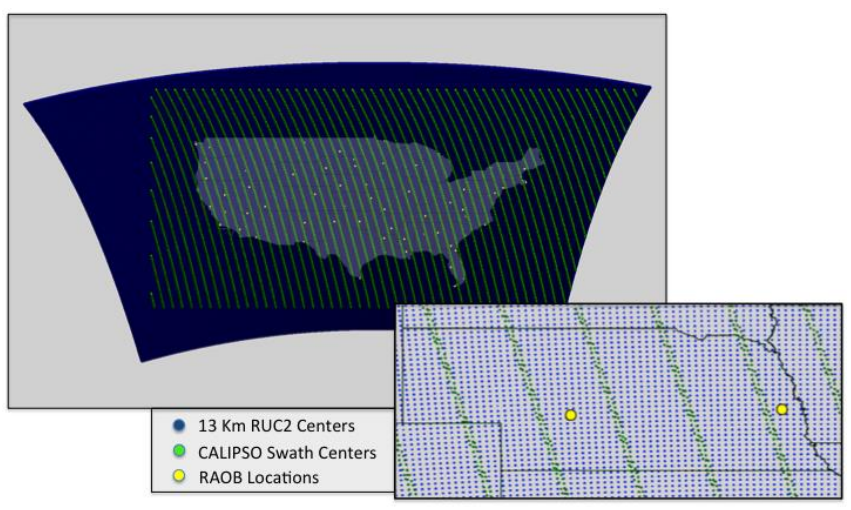

Figure 7. Illustration of the RUC2 (blue) centroids in relation to the CALIPSO lidar 5-km swath centers (green) over the contiguous United States. Yellow dots depict radiosonde locations. Note how lidar footprints and radiosonde locations often are not collocated (per the zoomed in image at lower right).

(CALIPSO) system were used as an independent measure of mixing height in this study. The CALIPSO satellite follows a sun-synchronous polar orbit with a 16-day repeat cycle (Vaughan et al. 2004). It is part of the Afternoon (A-Train) satellite constellation, which currently includes Global Change Observation Mission-Water 1, Aqua, CALIPSO, CloudSat, and Orbiting Carbon Observatory-2, where equatorial overpass time for CALIPSO is 1330 local time (NASA 2015). The Vertical Feature Mask (VFM, ver. 3.01) product was chosen for its simplicity (Fig. 8), as it is a postprocessed version of the aerosol backscatter and provides aerosol depth classification for all or individual constituents. Referencing Fig. 8, the horizontal footprint of the lidar beam is $5 \mathrm{~km}$, within which are 15 individual profiles at a horizontal resolution of $333 \mathrm{~m}$. The vertical resolution of each profile is $30 \mathrm{~m}$ within the first $8 \mathrm{~km}$ of the surface. The orange classification defines the total aerosol depth and was chosen to represent the mixed-layer depth ${ }^{5}$. For this definition, the base of the aerosol layer had to be in contact or within $60 \mathrm{~m}$ of the ground. The top of this aerosol layer defined the mixing height location. If elevated aerosol existed above this layer, and its horizontal width was $\geq 2.5 \mathrm{~km}$ (half or more of the $5-\mathrm{km}$ swath), a 60-m separation was allowed before a layer discontinuity was assumed. If the horizontal width of the elevated aerosol was $<2.5 \mathrm{~km}$, a discontinuous layer was assumed. The choice of $60 \mathrm{~m}$ for aerosol layer discontinuity detection represents twice the lidar verti-

\footnotetext{
5 The VFM algorithm is able to discriminate cloud and aerosol when they coexist and therefore mixing height was determined when clouds were present or not.
}

cal resolution and was found to be a representative filter to remove unrealistic gaps in the vertical (caused by minor beam attenuation). When employed, the local variability of the aerosol profile remained consistent with collocated numerical sounding structure.

The use of aerosol extinction-per the CALIPSO layer products - as a surrogate of the mixed-layer depth has been employed in other studies [namely, Leventidou et al. (2013) and $\mathrm{Wu}$ et al. (2010)]. The authors of the latter study found strong consistency with aerosol extinction and VFM classification in the context of mixing height determination. Note that consistent post-processing algorithms for VFM aerosol products influenced the two-year period chosen for this study (2009-2010). Further, unusable retrievals are not uncommon due to beam attenuation, and therefore, a subset of those depicted in Fig. 7 were found to be worthy of mixing height determination. Additional details regarding the CALIPSO system and data can found in Vaughan et al. (2004).

\section{e. Weather Research and Forecasting (WRF) data}

In conjunction with mixing heights computed at collocated points from RUC2 and lidar, an analysis also was conducted for three geographic regions using the mass core nonhydrostatic Advanced Research WRF model (Skamarock et al. 2008). Three modeling domains at $10-\mathrm{km}$ grid spacing, each with a one-way 2-km nest, were used for three regional extents over the Southeast, the northern Plains, and the western United States (Fig. 9). These subregions were selected in order capture a variety of airmass and terrain complexities that affect mixed-layer variability across the contiguous United States. The inner nest choice of 2$\mathrm{km}$ horizontal grid spacing followed the discussion presented in Moeng and Wyngaard (1988) in conjuncttion with the finest resolution options possible given local computing resources. The model configuration remained consistent for all three domains with 47 levels in the vertical extending up to $15 \mathrm{~km}$ above ground level (AGL), 18 vertical levels below $1.5 \mathrm{~km}$ AGL, with the lowest model level set at $10 \mathrm{~m}$ AGL. The model physics included (1) momentum and heat fluxes at the surface that use an Eta surface layer scheme following Monin-Obukhov similarity theory (Janjić 2001), (2) turbulence parameterization following the Mellor-Yamada-Nakanishi-Niino (MYNN; Nakanishi and Niino 2004) scheme, (3) convective processes following the Kain-Fritsch cumulus scheme for 10-km horizontal grid size, (4) cloud microphysical 


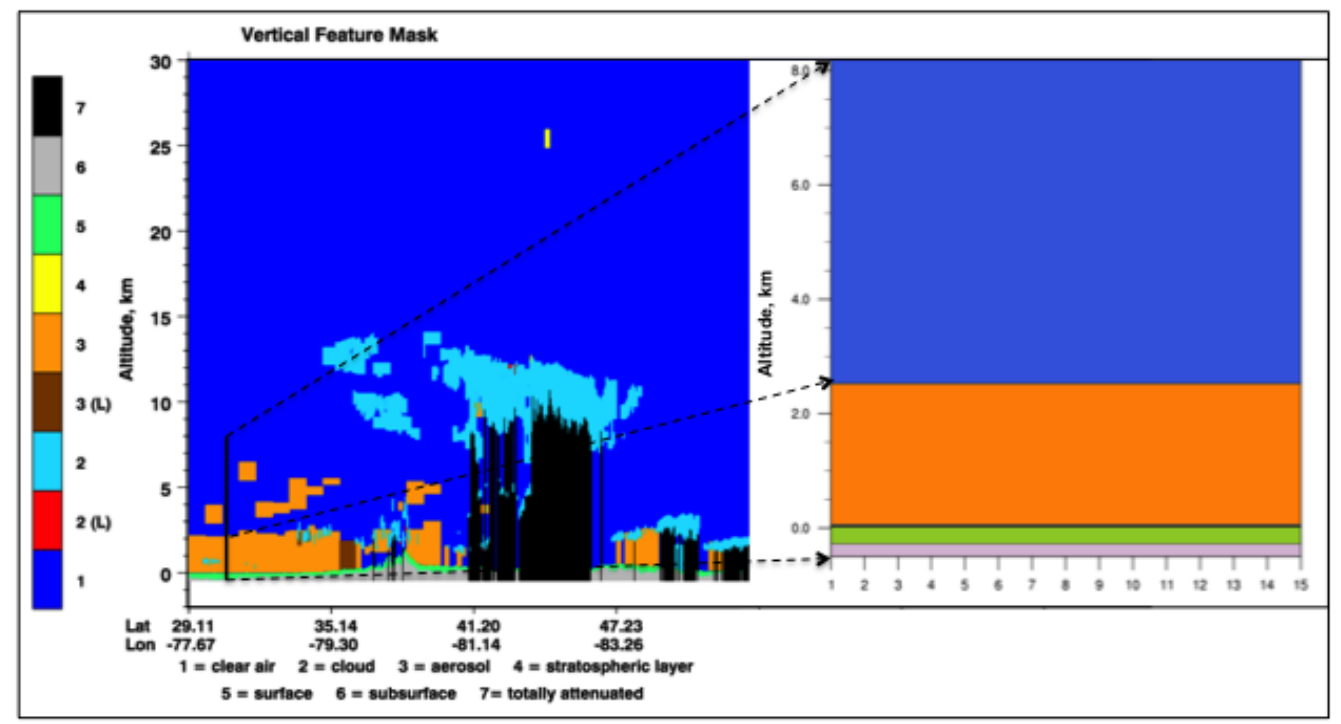

Figure 8. CALIPSO VFM browse image for a 5-km wide lidar footprint (south to north trajectory) and the associated feature classifications, where orange illustrates total aerosol within the column (left image). Footprint data are stored as sub-blocks comprising 15 individual profiles where the vertical and horizontal resolution of each profile is $60 \mathrm{~m} \times 333 \mathrm{~m}$, respectively, within the first $8 \mathrm{~km}$ (right image). In this example, mixing height would be approximately $2.5 \mathrm{~km}$ AGL.

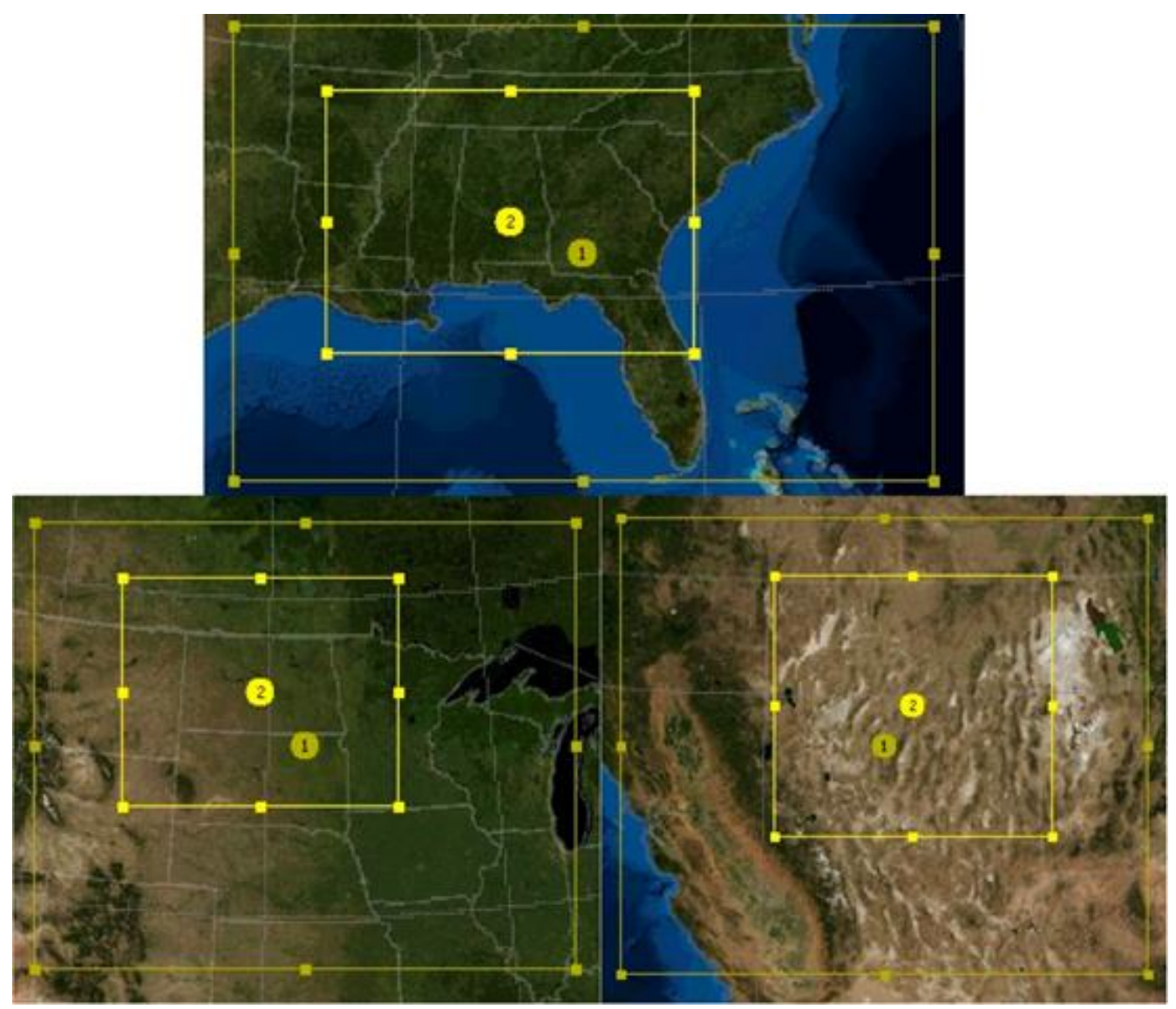

Figure 9. WRF nested domains for the Southeast (top), northern Plains (bottom left), and western United States (bottom right). The outer (inner) domain for each location was 10-km (2-km) grid spacing with each domain center denoted in yellow as 1 (2), respectively. 
processes following explicit bulk representation of microphysics (Thompson et al. 2004, 2006), (5) radiative processes parameterized using the Rapid Radiative Transfer Model for longwave radiation (Mlawer et al. 1997) and Dudhia's shortwave scheme (Dudhia 1989), and (6) the land-surface processes following the Noah land surface model that provides the surface sensible, latent heat, and upward longwave and shortwave fluxes to the atmospheric model (Chen and Dudhia 2001; Ek et al. 2003). Note that the MYNN turbulence parameterization for PBL was a critical choice for this study because the buoyancy and shear contributions from TKE are partitioned as separate output variables in WRF.

\section{f. Data analysis methods}

The analysis of afternoon mixing heights determined from RUC2, lidar, and WRF is presented in section 4. Values from the four methods were first examined in terms of their overall distributions from RUC2 versus lidar. A mixing height difference of 500 $\mathrm{m}$ was chosen to represent a significant discrepancy ${ }^{6}$. Such discrepancies were evaluated further using WRF model output for the three geographic regions (Fig. 9). The goal of the latter was to address two questions. First, does finer resolution in the horizontal (and vertical) explain height discrepancies among the methods because eddy motions and flux terms represented by the TKE equation would be better resolved? Second, what is the physical meaning of the mixing height produced by each method, in terms of the vertical structure and across space?

Methods employed to evaluate vertical structure included profile analysis of buoyancy, shear, and $\theta_{v}$. Colored maps of TKE contribution, partitioned by term for each 2-km domain, were developed to evaluate spatial variance. Mixing height differences $>500 \mathrm{~m}$ at a particular grid point assumed the following color assignment: 1) if buoyancy was present alone, points were colored red; 2) if shear was present alone, points were colored green; 3 ) if both terms were operative, points were colored blue; and 4) if neither term was operative, points were colored black, signifying that advection and/or topographic effects were active for an elevation $>250 \mathrm{~m}$. TKE contribution for buoyancy and shear was examined through perturbation values. Such

\footnotetext{
6 This value derives from Holzworth (1964) where the minimum mean annual mixing height range over the contiguous United States was found to be $200-800 \mathrm{~m}$. The $500-\mathrm{m}$ value represents the midpoint.
}

values were computed for each model level using the value at each grid point minus the average over the entire domain. These deviations were then integrated through the column for levels within the determined mixed-layer volume.

\section{Discussion of results}

\section{a. Mixing heights from RUC2 and lidar}

Figure 10 illustrates the distributions of mixing heights computed for all four methods using RUC2 data (light blue) versus those estimated from lidar (red). Overall, a low bias is prevalent across all method distributions with values from RI and Stull revealing a slightly larger variance. Examination of the median differences (departure from lidar) reveals deviations (rounded to the nearest integer) of 100, 200, 200, and $650 \mathrm{~m}$ for RI, Stull, TKE, and Holzworth, respectively. In the case of Holzworth, $450 \mathrm{~m}$ of the median deviation (the departure from Stull) corresponds directly to the exclusion of vapor content. As described in section 3a, the fundamental difference between the Holzworth and Stull mixing height calculation rests on the source variable, $\theta$ versus $\theta_{v}$, respectively. Therefore, if Holzworth heights were recomputed using $\theta_{v}$ instead of $\theta$, values would become synonymous with those from Stull.

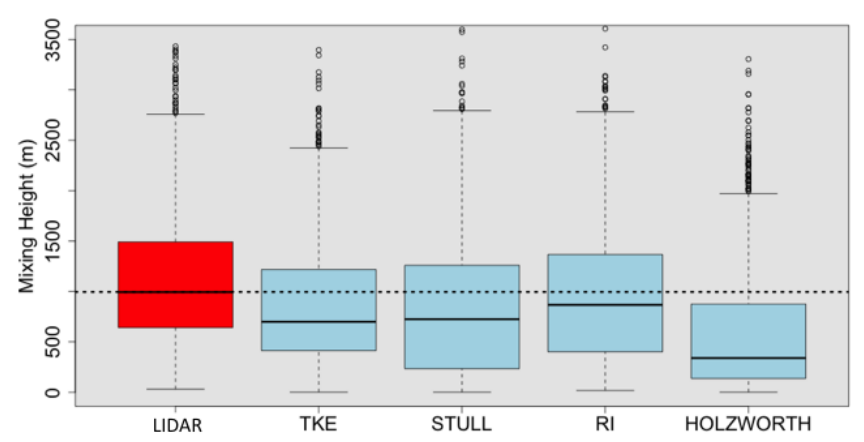

Figure 10. Boxplot diagrams of mixing heights derived from lidar (red) and RUC2 data for TKE, Stull, RI, and Holzworth (light blue, respectively). The black horizontal dashed line highlights the median height for lidar in relation to the four methods. The collocation sample size is 2151 .

Figure 11 is similar to Fig. 10, except scatter comparisons of height (each method versus lidar) are shown. One-to-one distribution trends are similar among TKE, Stull, and RI, and reaffirm the small median departures in Fig. 10, although variance and patterns of low bias are not consistent. Note the linear collection of points along the $x$ axis depicted in Stull and Holzworth versus lidar. For either method, a near 


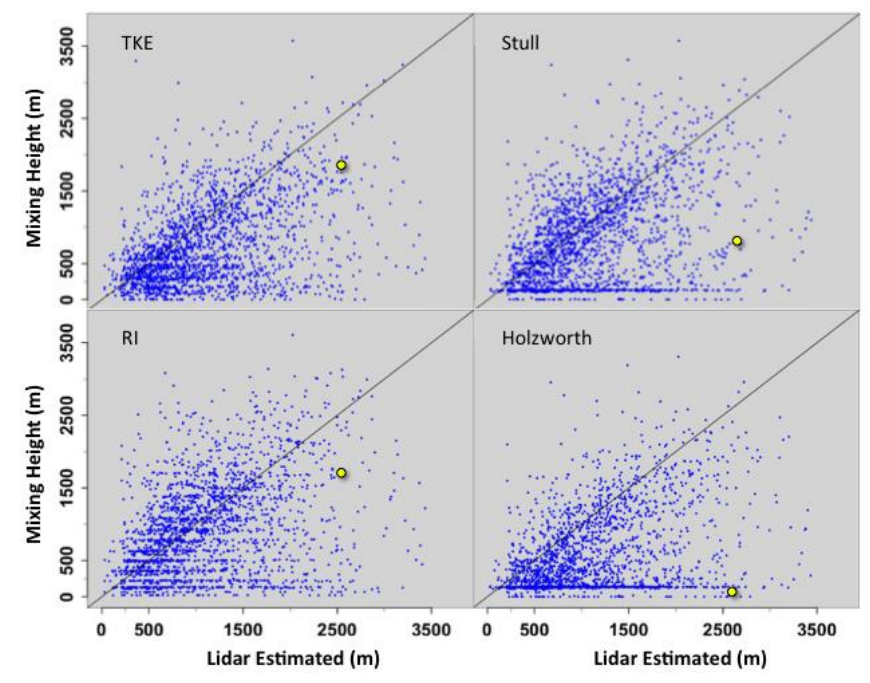

Figure 11. Four-panel scatter diagrams depicting mixing heights computed from RUC2 for each method versus lidar-derived height. The yellow highlighted points are discussed in Fig 12. The collocation sample size is 2151 .

zero height is indicative of a subtle low-level inversion prematurely capping the surface parcel buoyancy. Because this pattern is missing from the TKE and RI distributions, mixed-layer growth on these particular days was likely a result of dynamical forcing (e.g., shear) and that static-stability assessment alone was not sufficient. This situation can persist or be temporary depending on the meteorological environment (e.g., thermal capping or shear increasing, respectively). In persistent cases, inversion strength becomes important and is reflected by low mixing heights from all the methods. However, in the majority of cases, subtle near-surface inversions were properly resolved when vapor and/or wind shear are accounted for in the mixing height calculation. Figure 12 (related to the yellow points in Fig. 11) exemplifies such a scenario for a grid cell just west of Savannah, Georgia, at 1900 UTC 1 May 2009 (1500 local time) where a subtle, near-surface inversion in $\theta$ led to an underestimated mixing height from the Holzworth method (i.e., blue line in the amplified part of Fig. 12). The inclusion of moisture properly resolves the $\theta$ profile via the Stull method (red line), although the true depth of the mixed layer is function of static and dynamic stability per the values of TKE and RI (purple and green lines, respectively). The inclusion of both static and dynamic stability in the RI and TKE methods is reflected in their distributions against lidar (Fig. 11) where, in general, scatter is more symmetric about the one-to-one line. For the RI distribution, variance is larger overall and more evenly spread. The one-to-one relationship of

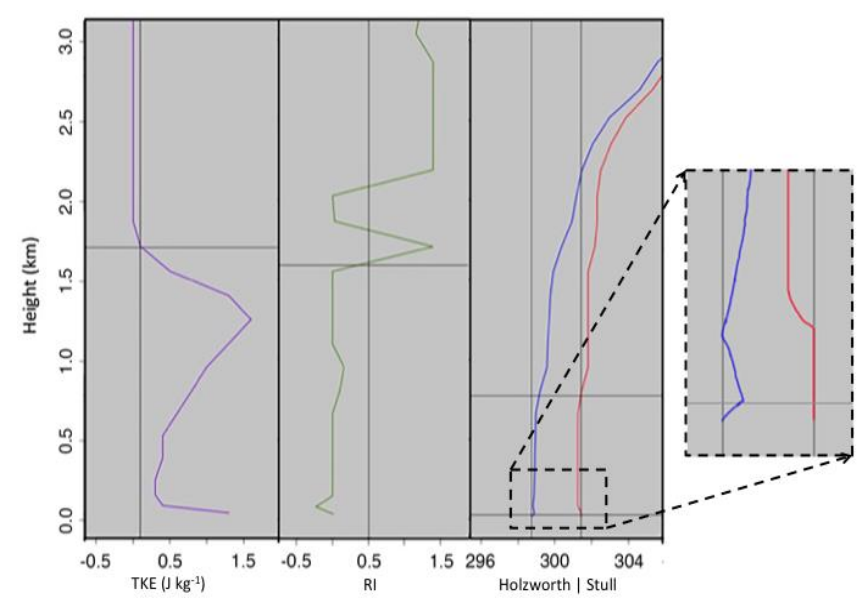

Figure 12. The vertical profiles of the yellow highlighted points in Fig. 11 at a grid cell just west of Savannah, Georgia, at 1900 UTC 1 May 2009. The profiles are shown over a 3-km depth for the TKE, RI, and combined Holzworth/Stull (blue/red lines; $\theta / \theta_{v}$ ) methods from left to right. Thin vertical black lines designate thresholds for the surface parcel temperature, and horizontal lines define the mixing heights. For the combined Holzworth/Stull panel, mixing heights (horizontal lines) are the bottom/top, respectively. The subtle near-surface inversion for the Holzworth method is shown in the blow-up panel (right-hand side) and marked by black dashed lines/arrows.

TKE versus lidar reveals less variance throughout, even though a low bias exists.

To quantify the distribution similarities, mixing heights from Stull, TKE, and RI (Holzworth excluded) were examined spatially. First, daily values from these three methods are presented as a combined mean, where the deviation from lidar (absolute value difference) at coincident locations is shown in Fig. 13. Red (black) dots represent differences $\geq 500 \mathrm{~m}(<500 \mathrm{~m})$. The percentage of red and black dots is $35 \%$ and $65 \%$ of the total, respectively. Figure 14 duplicates Fig. 13, except now the red (black) dots represent height deviations across the three methods only, with lidar height removed. Now, the percentage of red and black dots is $15 \%$ and $85 \%$, respectively. These two calculations reveal that large height differences (across methods) occur $15 \%$ of time, and when the method results are combined, mean values differ from lidar $20 \%$ of the time (i.e., $35 \%$ minus 15\%). Height discrepancies per method likely are produced because of dynamical processes, where method inclusion (or not) and the level of representation of the dynamics terms impact the mixing height. The $20 \%$ departure from lidar height also may suggest mixing height overestimation from lidar where the vertical distribution of aerosol is not always fully representative, particularly the upper bound. 


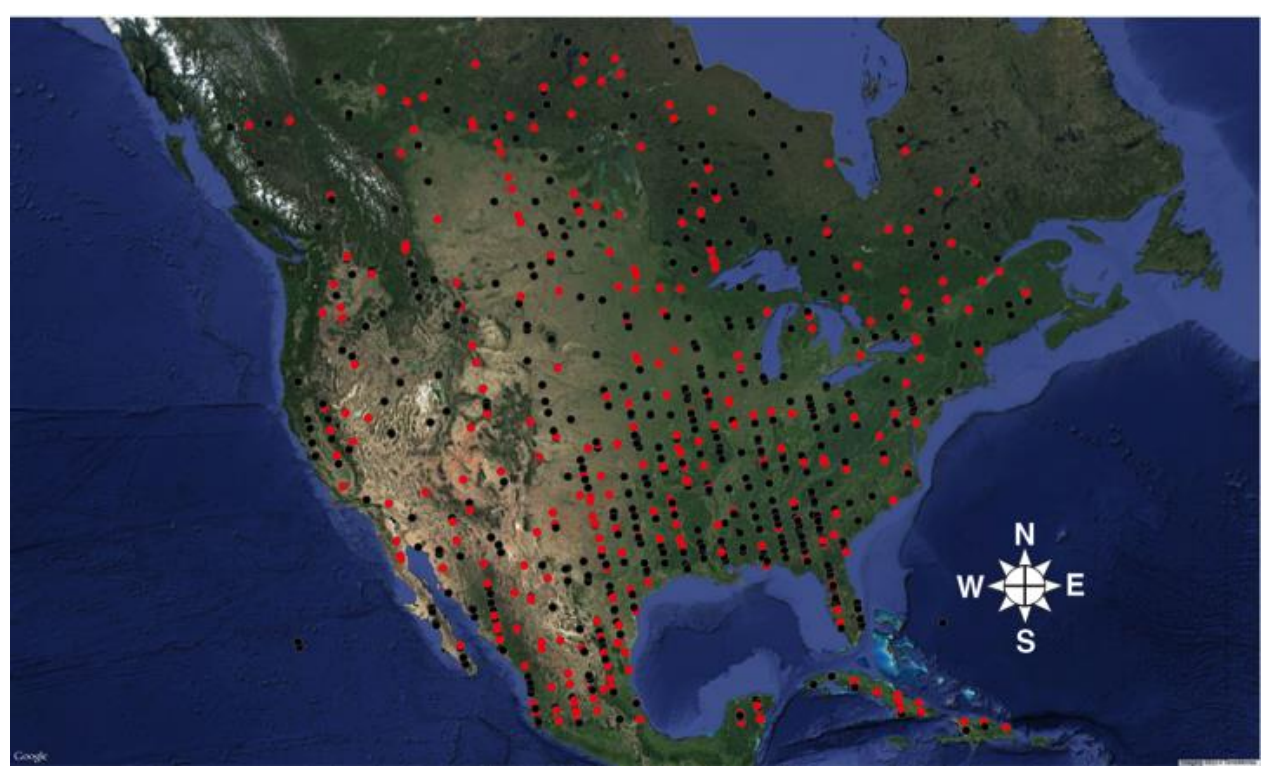

Figure 13. Map of absolute mixing height differences, derived as the combined mean height (for Stull, TKE, and RI from the RUC2) minus the coincident lidar height. Red (black) dots indicate values $\geq 500 \mathrm{~m}(<500 \mathrm{~m})$, respectively.

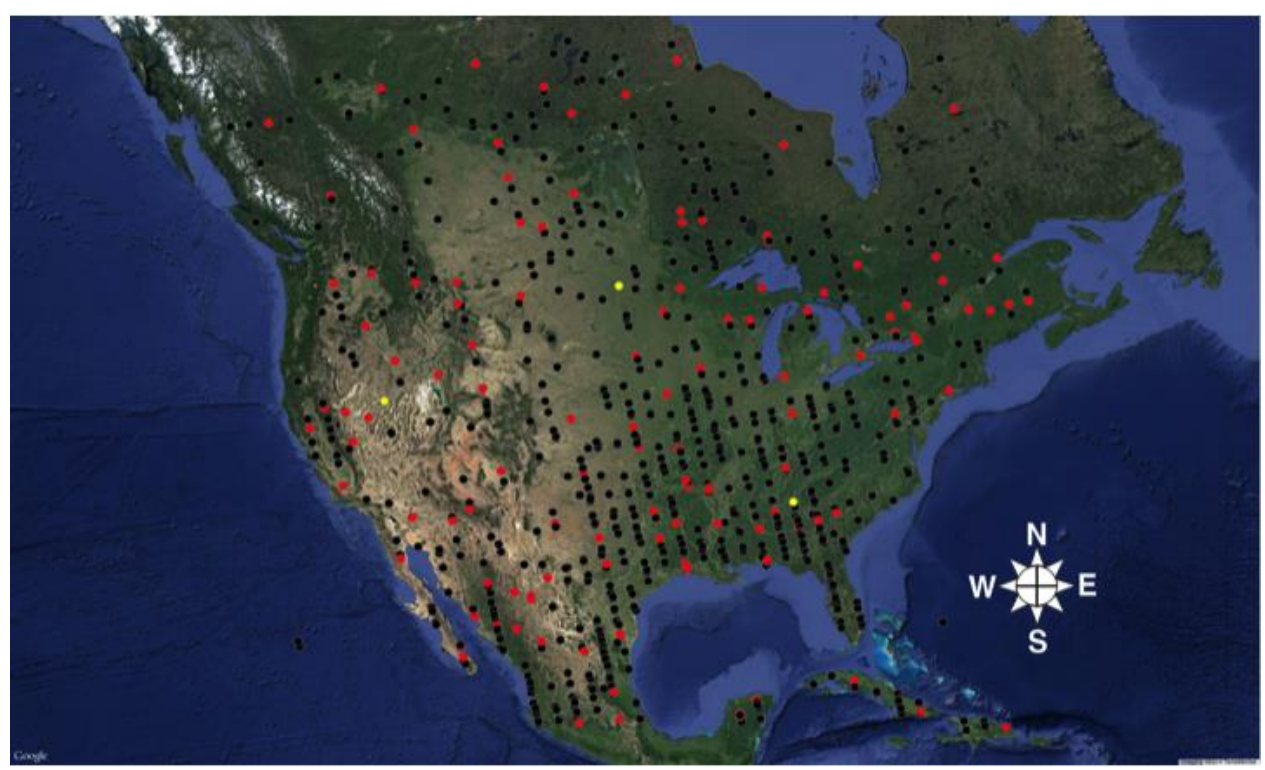

Figure 14. Map of absolute mixing height difference across methods (for TKE, RI, and Stull) from RUC2 (lidar excluded). Red (black) dots indicate differences $\geq 500 \mathrm{~m}(<500 \mathrm{~m})$. The three yellow dots identify locations examined as case studies for the Southeast, northern Plains, and the western United States (from east to west); refer to Table 2.

Lidar height being an overestimate is conjecture, but could have merit under the following circumstances. For instance, mixing height estimation from lidar is defined by the aerosol termination or the first sizeable discontinuity with height, per the VFM product described in section $3 \mathrm{~d}$. What if the aerosol top was not sharply delineated, but instead diffused across the mixed-layer boundary as a result of the entrainment process (e.g., Fig. 3)? In the entrainment zone, internal fluid properties of heat, moisture, and momentum from the mixed-layer air below are vigorously stirred with the air above (from the free atmosphere). Therefore, the delineation of aerosol particles may be a function of the entrainment intensity and the derived mixing height may be accurate to within a few hundred meters. Of course, the quantity and type of 
aerosol present has implications on this theory. Aerosol type (e.g., dust, smoke, continental versus marine) was examined for several locations, and type discrimination did not impact the altitude of the aerosol top. In addition, the confidence value provided for feature classification (e.g., aerosol versus cloud particle or other) was examined. Restriction of pixels associated with lower confidence did not impact results.

\section{b. Mixing height differences-evaluation of vertical structure using WRF}

For this exercise, data for each of the three yellow dots in Fig. 14 identified a significant mixing height difference or discrepancy among the TKE, Stull, and RI methods. Regional classification names (Southeast, northern Plains, and western United States) were used to reference each point. Table 2 shows the breakdown of mixing heights for each location for both the RUC2 and WRF model output. Lidar mixing heights also are given. Holzworth heights were excluded from this analysis simply because the method mechanics are identical to the surface parcel displacement used for Stull where the use of vapor content is the only outstanding difference in the calculation.

Table 2. RUC2/WRF mixing heights from the TKE, Stull, and RI methods, as well as lidar (CALIPSO), for the three case study locations (yellow dots in Fig. 14).

\begin{tabular}{|c|c|c|c|}
\hline & \multicolumn{3}{|c|}{ Mixing Height (m) } \\
\hline Method & Southeast & $\begin{array}{c}\text { Northern } \\
\text { Plains }\end{array}$ & $\begin{array}{c}\text { Western } \\
\text { United States }\end{array}$ \\
\hline TKE & $1444 / 2184$ & $3026 / 2519$ & $1415 / 3439$ \\
\hline Stull & $2022 / 2089$ & $1102 / 2661$ & $2652 / 2905$ \\
\hline RI & $1931 / 1659$ & $837 / 1419$ & $2194 / 2616$ \\
\hline Lidar & 1965 & 2995 & 1846 \\
\hline
\end{tabular}

For RUC2 at the Southeast location there is a discrepancy in the TKE value relative to the Stull, RI, and lidar values, which are within $100 \mathrm{~m}$ of each other. Using WRF data, the discrepancy was improved for TKE, although the RI value was a slight underestimate. Further evaluation follows in Fig. 15 where profiles of TKE-buoyancy (red), TKE-shear (green), and $\theta_{v}$ (blue) are illustrated at 5-min intervals for the afternoon (1705-0000 UTC). In this case, dissipation of the TKE-buoyancy/shear and the extent of surface parcel buoyancy approximately coincide [i.e., the intersection of the yellow curve(s) at 0 in the left panel and with the vertical black line in the right panel]. Additional TKE-buoyancy/shear and surface parcel rise does occur following the lidar sample time, as

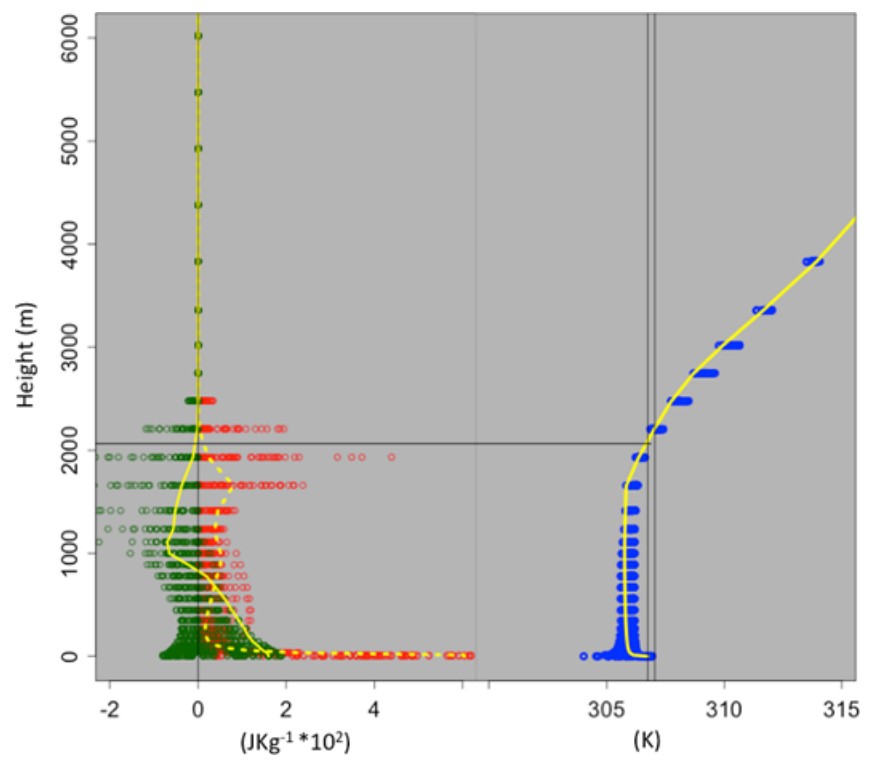

Figure 15. Illustration of TKE-buoyancy (red) and TKE-shear (green) profiles in the left panel and $\theta_{v}$ (blue) profile in the right panel for 1705-0000 UTC at 5-min intervals for the Southeast location. Yellow curves represent the 1900 UTC lidar sample time and corresponding profiles for TKE-buoyancy (dashed) and TKEshear (solid) in the left panel and $\theta_{v}$ (solid) in the right panels. The black vertical lines in the right panel highlight the surface parcel upward displacement for the maximum and 1900 UTC.

noted by the slightly elevated red/green and blue points, respectively, above the horizontal black line. Figure 16 shows the vertical structure of mixing height for the 1705-0000 UTC time period depicted for the three methods. Note the intersection of the Stull and TKE heights near the lidar sample time. Over the remaining afternoon hours, the TKE height eventually exceeded the Stull height with RI values remaining lower. The latter emphasizes the importance of other dynamical forcing (e.g., advection) likely contributing to TKE height along with TKE-buoyancy/shear perturbation components missing in the RI calculation.

A second example for the point in the northern Plains is shown in Table 2 and Fig. 17. In this case, there is a large height discrepancy across all methods where the TKE height is over $2000 \mathrm{~m}$ greater from the RUC2. However, discrepancies are fairly well resolved for the WRF TKE and Stull heights. Results illustrated in Figs. 17 and 18 are consistent with the previous example and follow the same description.

A third example for a point in the western United States, in central Nevada, is shown in Table 2 and Fig. 19. In this case, the TKE height discrepancy from RUC2 is improved but a $431-\mathrm{m}$ difference remains between TKE and lidar values. Unlike the two previous cases, there is a much deeper contribution from 


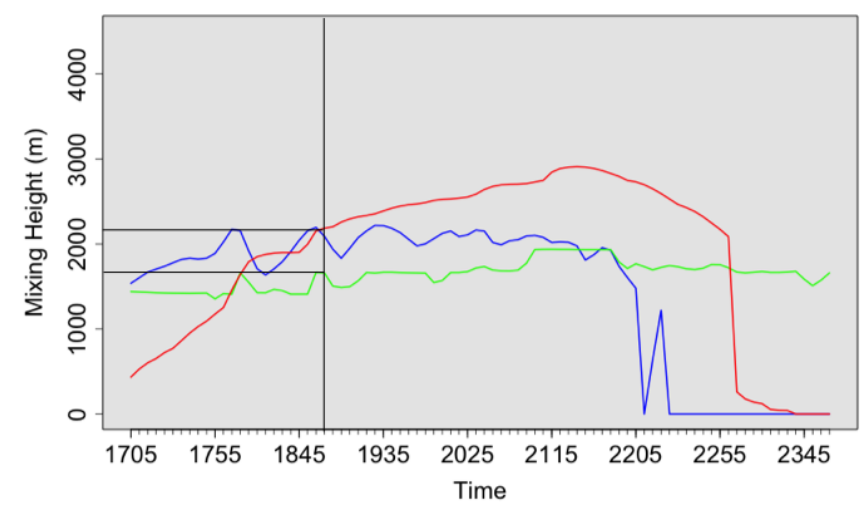

Figure 16. Time-height profile of mixing heights for TKE (red), Stull (blue), and RI (green) from the WRF for the Southeast location. Temporal resolution is every $5 \mathrm{~min}$ from 1705-0000 UTC. Vertical and horizontal black lines highlight the 1900 UTC lidar sample time (consistent with the yellow curves in Fig. 15) and mixing height location, respectively.

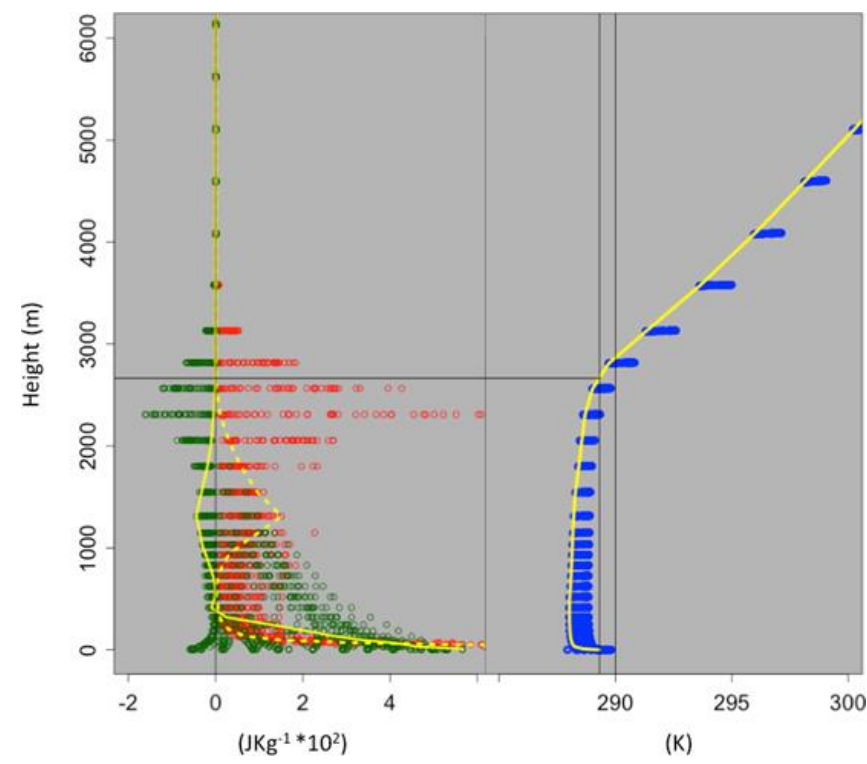

Figure 17. Same as Fig. 15 except for the northern Plains where the yellow curves identify the 2000 UTC lidar sample time.

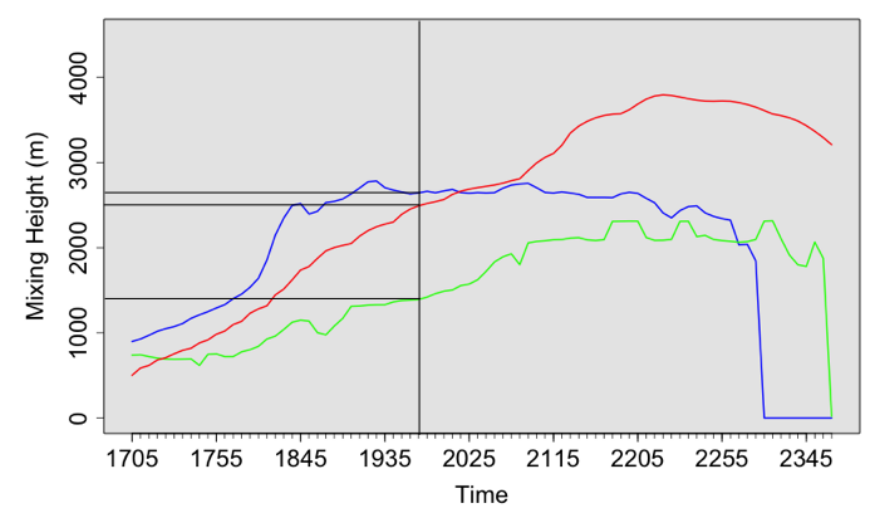

Figure 18. Same as Fig. 16 except for the northern Plains where the black vertical line corresponds to the 2000 UTC lidar sample time.

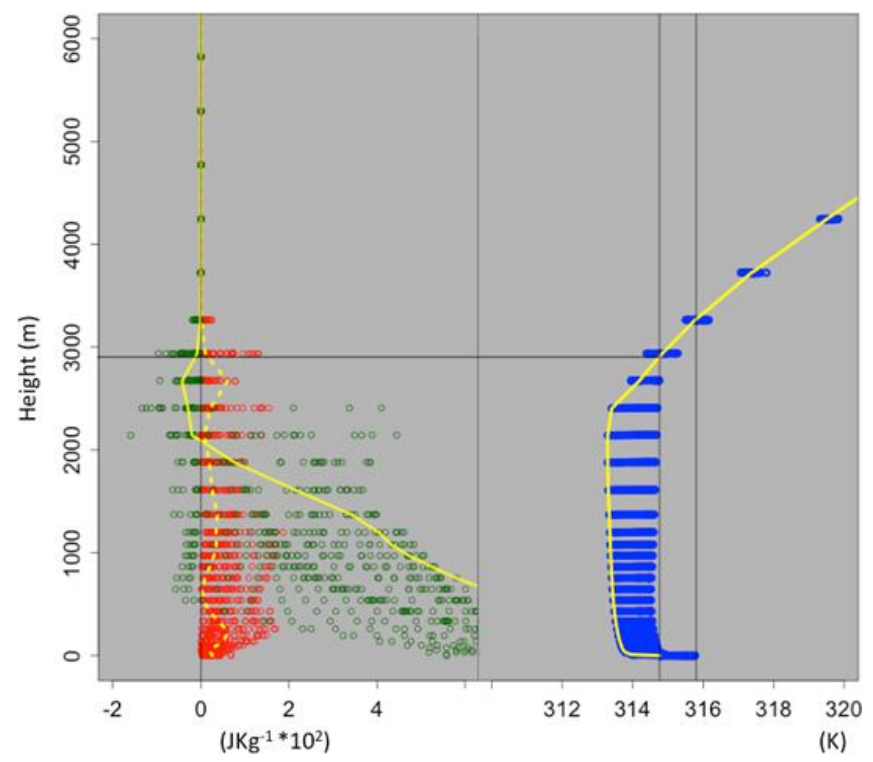

Figure 19. Same as Fig. 15 except for the western United States the where yellow curves identify the 2100 UTC lidar sample time.

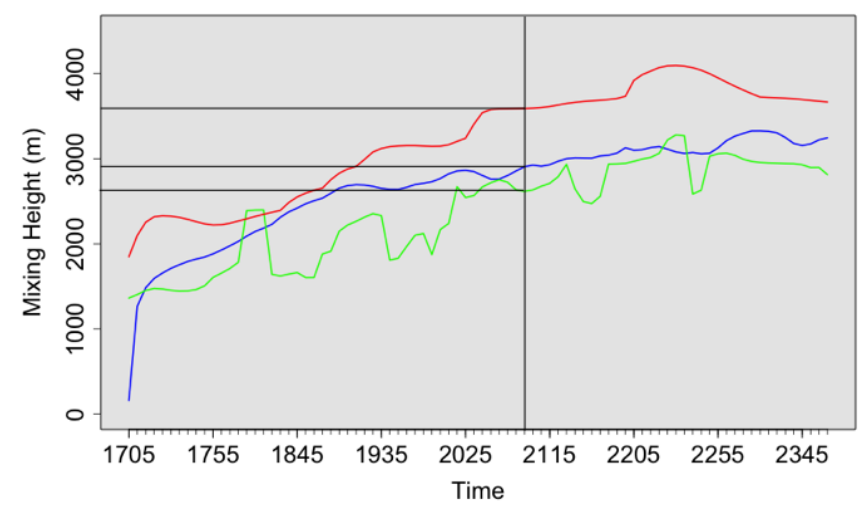

Figure 20. Same as Fig. 16 except for the western United States where the black vertical line corresponds to the 2100 UTC lidar sample time.

TKE-shear (Fig. 19, solid yellow curve in left panel). Greater TKE-shear likely corresponds to the presence of complex terrain, and with a heterogeneous mountain-valley landscape like central Nevada, daytime upslope flow accelerations in response to surface heating are common. Like the two previous examples, mixing heights from the three methods follow a similar trend during the afternoon (Fig. 20).

Mixing height determination with higher resolution numerical soundings better resolves the method discrepancies. Values from TKE and Stull appear to collapse on each other for a period before an elevated separation develops during the mid- to late-afternoon where TKE calculates a higher value. The question then becomes, is a consistently higher value from TKE a result of perturbation terms; is it a function of addi- 
tional terms in the TKE equation (e.g., advection); or, is TKE and its chosen threshold simply an overestimate? In the next subsection, a spatial analysis of TKE-buoyancy/shear perturbations, including terrain aspects, sheds more light on this discussion. RI is not included in the remaining analysis as it truly is a proxy for TKE with a more conservative threshold.

\section{c. Mixing height differences-evaluation of spatial variance using WRF}

Figure 21 (left panel) illustrates the mixing height differences between the methods (TKE minus Stull) over the Southeast WRF 2-km grid-spacing domain. Differences appear subtle owing to the fine resolution, but are present nonetheless. The center panel of Fig. 21 portrays the differences in terms of the perturbations using the grid cell coloring approach (section $3 \mathrm{f}$ ). Higher TKE values owing to buoyancy are present in isolated locations. Green (shear) and blue (buoyancy and shear) cells are noteworthy where the low-level flow field (largely anticyclonic, Fig. 21, right panel) has slight speed/directional changes imbedded. Contributions also are evident near terrain rises and coastlines where the upstream flow is orthogonal. The most interesting differences are located on the leeward slope of the southern Appalachians over western North Carolina, where Stull values exceed those from TKE. This pattern is consistent with leeward airmass descent and warming in the surface layer at the lower elevation. This conjecture is supported by the northwesterly flow upstream, which is orthogonal to higher terrain on approach, where the air rises (descends) and cools (warms) on the windward (leeward) slope. In this situation, a strong superadiabatic surface layer ensues at lower elevation southeast of the higher terrain and the low-level parcel buoyancy is maximized. This discrepancy between Stull and TKE values was found to be temporary $(\sim 2 \mathrm{~h})$, as the air column mixed vertically, with TKE eventually portraying an elevated value similar to the profile examples. Overall, higher TKE values are well explained via perturbation components of buoyancy and shear, suggesting that elevated values are a byproduct.

Figure 22 portrays a second example for a $2-\mathrm{km}$ grid-spacing WRF domain over the northern Plains. Here, larger TKE values dominate again with a few isolated Stull values over southern North Dakota (left panel). As before, the larger Stull values were found to be temporary. In this situation, the low-level flow is confluent overall with cyclonic and anticyclonic re- gimes, northwest and southeast, respectively (right panel), amplifying the westerly advection (right panel). There are some impressive terrain rises in western South Dakota and eastern Wyoming, not excluding the moderate high points in west-central Minnesota. These locations reveal larger TKE values (left and center panel) orchestrated by terrain rises and orthogonal advection upstream. Elsewhere, perturbations in buoyancy and shear independently or together promote larger TKE values.

Figure 23 represents a third spatial example over the western United States highlighting central Nevada. Complex terrain dominates the landscape with predominately weak southerly flow (right panel). There are several north-south mountain ranges across Nevada, and mixing height differences are found along these features (left panel). In this example, higher Stull values are more evident, which are largely explainable owing to superadiabatic surface layers. As before, such differences were found to be temporary and surpassed by TKE. Shear-based differences are scattered across central-eastern Nevada in the presence of light/ variable flow (center and right panel). Elsewhere, differences are explained by buoyancy alone or together with shear.

Overall, larger mixing height differences (TKE versus Stull) are well explained by the spatial perturbation analysis. Grid cells of perturbation types were collocated with large height differences $(>500 \mathrm{~m})$. Buoyancy perturbations also were found in grid cells where height differences were $<500 \mathrm{~m}$; however, the magnitude of the perturbation was reduced. The same can be said for shear- and terrain-induced perturbations, including advective-based perturbations, unless the flow was highly amplified, curved, or orthogonal to topographic irregularities. These findings in combination with TKE's robust account of all turbulent motion sources-particularly those associated with dynamical processes - explain why height differences exist between these two methods.

\section{Discussion of results}

In this study, mixing heights from four methods (TKE, Stull, RI, and Holzworth) were examined. Results from each method were compared with one another and against lidar-derived mixing height estimates. A series of diagnostic analyses also was conducted over space and time for point locations and spatial extent where topographic features and airmass exposure are highly variable. Table 3 provides a break- 


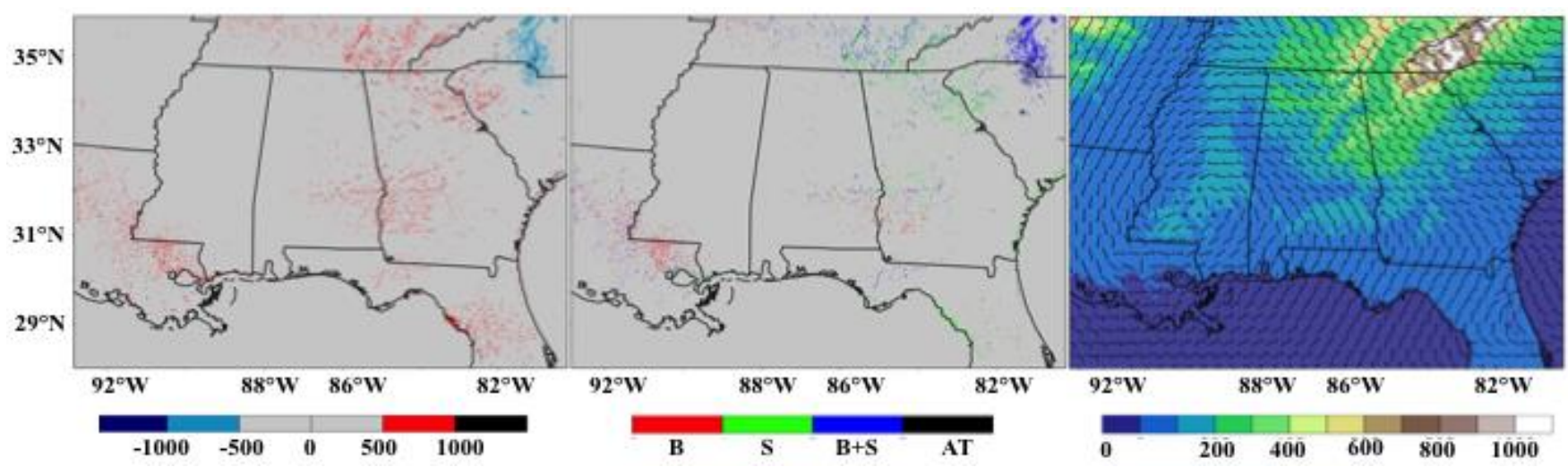

Figure 21. Maps of TKE-Stull height differences ( $\mathrm{m}$, left), spatial perturbations (center), and terrain (m) overlain by the 850-mb wind (kt) for the Southeast 2-km grid-spacing WRF domain. Perturbation occurrence is represented by color for buoyancy (red, B), shear (green, S), buoyancy and shear (blue, B+S), and advection and/or terrain inducement (black, AT).

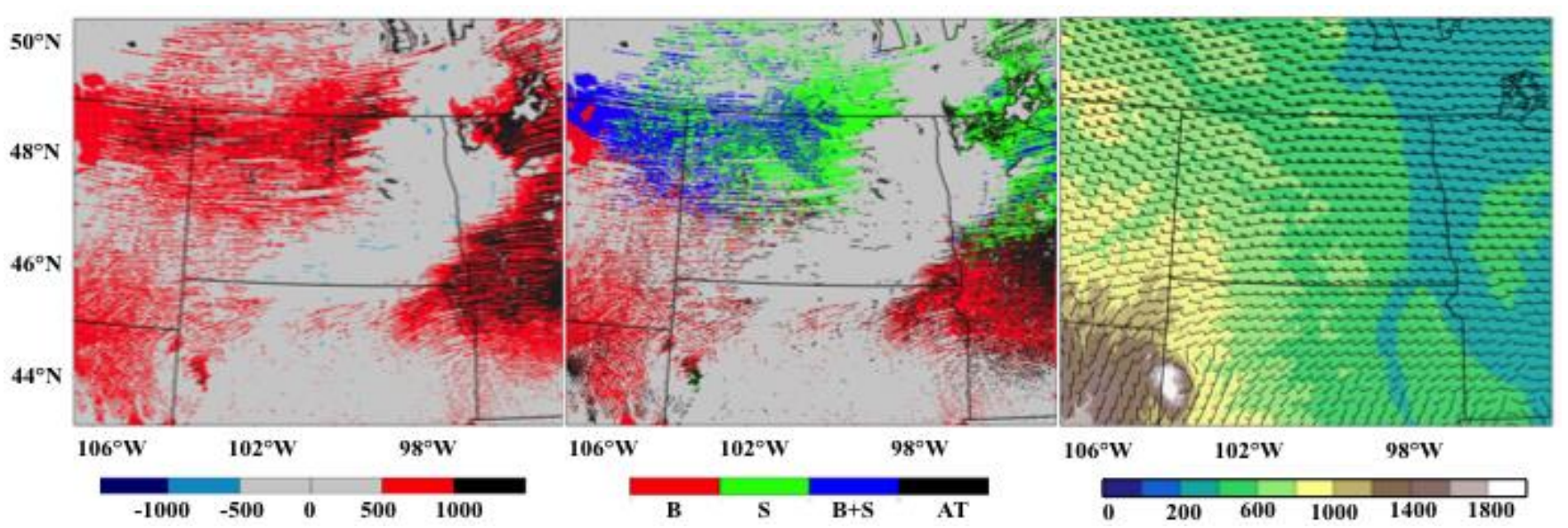

Figure 22. Same as Fig. 21 except for the northern Plains domain.

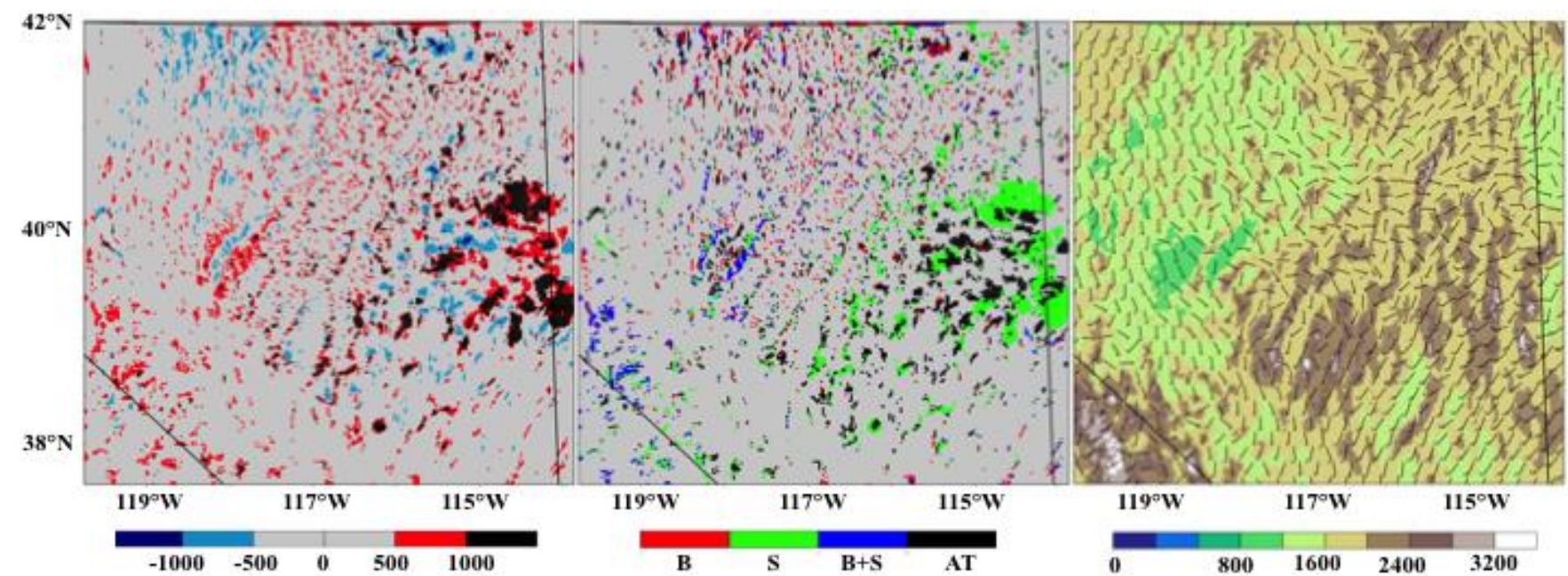

Figure 23. Same as Fig. 21 except for the western United States domain with the 700-mb level representing the flow field (right).

down of advantages and disadvantages for each method.

The TKE method stands out as the most robust in terms of inclusiveness of both thermodynamic and dynamic processes in the boundary layer. Lee et al. (2008) discussed how TKE may be an overestimate of the true mixed-layer depth owing to the entrainment of TKE by horizontal and vertical advection and diffu- 
Table 3. Summary of mixing height method advantages and disadvantages.

\begin{tabular}{|c|c|c|}
\hline Method & Advantages & Disadvantages \\
\hline TKE & $\begin{array}{l}\text { - Incorporates all turbulent sources/sinks (buoyancy, } \\
\text { shear, advection, terrain influence, and others) }\end{array}$ & - Fine-resolution model dependency (e.g., $\leq 5$-km grid spacing) \\
\hline RI & $\begin{array}{l}\text { - Not model dependent } \\
\text { - Buoyancy and shear } \\
\text { - Surrogate for TKE dominant terms }\end{array}$ & $\begin{array}{l}\text { - Mean profile state exclusively, turbulent perturbations excluded } \\
\text { - Excludes advection }\end{array}$ \\
\hline Stull & $\begin{array}{l}\text { - Not model dependent } \\
\text { - Diagnostic method for entire profile } \\
\text { - Quick interpretation }\end{array}$ & $\begin{array}{l}\text { - Mean profile state exclusively, turbulent perturbations excluded } \\
\text { - Buoyancy only }\end{array}$ \\
\hline Holzworth & $\begin{array}{l}\text { - Not model dependent } \\
\text { - Quick interpretation }\end{array}$ & $\begin{array}{l}\text { - Mean profile state exclusively, turbulent perturbations excluded } \\
\text { - Dry atmosphere } \\
\text { - Surface parcel buoyancy only }\end{array}$ \\
\hline
\end{tabular}

sion processes near the PBL top using the 12-km NAM model. However, these processes facilitate mixing through the entire column and precise discrimination near the PBL top may require reexamination of a chosen TKE threshold (e.g., $0.1 \mathrm{~J} \mathrm{~kg}^{-1}$ ). Case examples shown in this paper demonstrate that large mixing height differences occur when dynamical processes influence the overall calculation (e.g., 15\% of the time, Fig. 14 and section 4a). Mixing height sensitivity to shear and buoyancy perturbations, including advection, as shown in section $4 \mathrm{~d}$, also demonstrates the importance of dynamical processes and that a numerical formulation of TKE is required to capture such processes.

The Stull method proves to be a reasonable approach to mixed-layer height estimation. However, the method relies on parcel theory and displacement thermodynamics only. The RI approach is an attempt to remedy dynamical exclusion, but advective processes and perturbation components are not included. The use of the RI flux number-inclusive of perturbation components - would be a more complete treatment. However, use of the latter, like TKE, would require a numerical model to calculate perturbation terms.

As mentioned earlier, the use of the Holzworth method is discouraged overall. Its use in arid locales when low humidities are present has merit; however, the viewpoint of the unsaturated atmosphere via $\theta_{v}$ accommodates both dry and moist situations. Therefore, use of $\theta$ for this application is unnecessary.

Based on the findings of this study, the authors recommend the TKE method for operational mixing height prediction. And although this method requires a fine-resolution numerical model of at least $5-\mathrm{km}$ horizontal grid spacing ${ }^{7}$, this approach yields a derived

\footnotetext{
${ }^{7}$ The 5-km assertion (corresponding to fine resolution) is based on the lidar swath resolution used in this study, the discussion in Moeng and Wyngaard (1988), and the current NAM Nest horizontal grid spacing of $4 \mathrm{~km}$ over the continental United States.
}

mixing height inclusive of both thermodynamic and dynamic processes where the mixing budget in the vertical and horizontal is quantified using a prognostic equation as part of a numerical PBL scheme. An alternative to TKE-based mixing height is the diagnostic variable "PBL height," which is available as part of operational NAM model output. The RI and Stull methods are both sound diagnostic approaches with minor shortcomings (see Table 3), but represent viable alternatives when numerical model output with TKE is unavailable.

Acknowledgments. The authors thank Joseph J. Charney, Scott L. Goodrick, Michael L. Kaplan, John M. Lewis, Brian E. Potter, and John Tomko for their constructive comments and editorial assistance. We are grateful to Erin C. Gleason for her assistance with graphics, and acknowledge NWA JOM Editors Jon Zeitler and Michael C. Coniglio, and the three reviewers, who provided comments that improved the manuscript. The authors also acknowledge the cooperation and collaboration of the U.S. Department of Energy as part of the Atmospheric Radiation Measurement Climate Research Facility who provided the RUC2 analysis grids used in this study. Partial support for this project was provided by the USDA Forest Service California and Nevada Smoke and Air Committee Agreement Number 09-CS-11052012-266 and the USDA Forest Service National Interagency Fire Center Agreement Number 11-CS-11130206-075.

\section{REFERENCES}

Ball, F. K., 1960: Control of inversion height by surface heating. Quart. J. Roy. Meteor. Soc., 86, 483-494, CrossRef.

Benjamin, S. G., G. A. Grell, J. M. Brown, T. G. Smirnova, and R. Bleck, 2004: Mesoscale weather prediction with the RUC hybrid isentropic-terrain-following coordinate model. Mon. Wea. Rev., 132, 473-494, CrossRef. 
Betts, A. K., 1973: Non-precipitating cumulus convection and its parameterization. Quart. J. Roy. Meteor. Soc., 99, 178-196, CrossRef.

Burk, S. D., and W. T. Thompson, 1989: A vertically nested regional numerical weather prediction model with second-order closure physics. Mon. Wea. Rev., 117, 2305-2324, CrossRef.

Chen, F., and J. Dudhia, 2001: Coupling an advanced land surface-hydrology model with the Penn State-NCAR MM5 modeling system. Part I: Model implementation and sensitivity. Mon. Wea. Rev., 129, 569-585, CrossRef.

Dudhia, J., 1989: Numerical study of convection observed during the Winter Monsoon Experiment using a mesoscale two-dimensional model. J. Atmos. Sci., 46, 30773107, CrossRef.

Ek, M. B., K. E. Mitchell, Y. Lin, E. Rogers, P. Grunmann, V. Koren, G. Gayno, and J. D. Tarpley, 2003: Implementation of Noah land surface model advances in the National Centers for Environmental Prediction operational mesoscale Eta model. J. Geophys. Res., 108, 8851, CrossRef.

Fearon, M. G., 2000: The use of nonlocal static stability to determine mixing height from NCEP Eta model output over the Western U.S. M.S. thesis, Dept. of Atmospheric Sciences, University of Nevada, $161 \mathrm{pp}$. [Available online at www.cefa.dri.edu/Publications/ mfearon msthesis.pdf.]

Holtslag, A. A. M., and C.-H. Moeng, 1991: Eddy diffusivity and countergradient transport in the convective atmospheric boundary layer. J. Atmos. Sci., 48, 16901698, CrossRef.

Holzworth, G. C., 1964: Estimates of mean maximum mixing depths in the contiguous United States. Mon. Wea. Rev., 92, 235-242, CrossRef.

1967: Mixing depths, wind speeds and air pollution potential for selected locations in the United States. $J$. Appl. Meteor., 6, 1039-1044, CrossRef.

Janjić, Z. I., 2001: Nonsingular implementation of the Mellor-Yamada Level 2.5 scheme in the NCEP Meso model. NCEP Office Note No. 437, 61 pp. [Available online at www.lib.ncep.noaa.gov/ncepofficenotes/files/ on437.pdf.]

Jeričević, A., and B. Grisogono, 2006: The critical bulk Richardson number in urban areas: Verification and application in a numerical weather prediction model. Tellus A, 58, 19-27, CrossRef.

Kiefer, M. T., W. E. Heilman, S. Zhong, J. J. Charney, and X. Bian, 2015: Mean and turbulent flow downstream of a low-intensity fire: Influence of canopy and background atmospheric conditions. J. Appl. Meteor. Climatol., 54, 42-57, CrossRef.

Lee, P., and Coauthors, 2008: Impact of consistent boundary layer mixing approaches between NAM and CMAQ. Environ. Fluid Mech., 9, 23-42, CrossRef.
Leventidou, E., P. Zanis, D. Balis, E. Giannakaki, I. Pytharoulis, and V. Amiridis, 2013: Factors affecting the comparisons of planetary boundary layer height retrievals from CALIPSO, ECMWF and radiosondes over Thessaloniki, Greece. Atmos. Environ., 74, 360366, CrossRef.

Lewis, J. M., 2007: Use of a mixed-layer model to investigate problems in operational prediction of return flow. Mon. Wea. Rev., 135, 2610-2628, CrossRef.

Lilly, D. K., 1968: Models of cloud-topped mixed layers under a strong inversion. Quart. J. Roy. Meteor. Soc., 94, 292-309, CrossRef.

McCarthy, J. E., 2005: Clean Air Act: A summary of the act and its major requirements. CRS Report for Congress, Order Code RL30853, 25 pp. [Available online at fpc.state.gov/documents/organization/47810.pdf.]

Mlawer, E. J., S. J. Taubman, P. D. Brown, M. J. Iacono, and S. A. Clough, 1997: Radiative transfer for inhomogeneous atmospheres: RRTM, a validated correlated-k model for the longwave. J. Geophys. Res., 102, 16663-16682, CrossRef.

Moeltner, K., M.-K. Kim, E. Zhu, and W. Yang, 2013: Wildfire smoke and health impacts: A closer look at fire attributes and their marginal effects. J. Environ. Econ. Manag., 66, 476-496, CrossRef.

Moeng, C.-H. and J. C. Wyngaard, 1988: Spectral analysis of large-eddy simulations of the convective boundary layer. J. Atmos. Sci., 45, 3573-3587, CrossRef.

Nakanishi, M., and H. Niino, 2004: An improved MellorYamada Level-3 model with condensation physics: Its design and verification. Bound-Lay Meteorol., 112, 131, CrossRef.

NASA, cited 2015: The Cloud-Aerosol Lidar and Infrared Pathfinder Satellite Observation (CALIPSO). [Available online at www-calipso.larc.nasa.gov.]

Pasquill, F., 1961: The estimation of the dispersion of windborne material. Meteor. Mag., 90, 33-49.

Richardson, L. F., 1921: Some measurements of atmospheric turbulence. Philos. Trans. R. Soc., A, 221, 1-28, CrossRef.

Seibert, P., F. Beyrich, S.-E. Gryning, S. Joffre, A. Rasmussen, and P. Tercier, 1997: Mixing height determination for dispersion modelling. European Commission, COST Action 710, Report of Working Group 2, 121 pp. [Available online at imp.boku.ac.at/ envmet/finalreport_cost710-2.pdf.] , and _ 2000: Review and intercomparison of operational methods for the determination of the mixing height. Atmos. Environ., 34, 1001-1027, CrossRef.

Skamarock, W. C., and Coauthors, 2008: A Description of the Advanced Research WRF Version 3. NCAR Tech. Note NCAR/TN-475+STR, 125 pp. [Available online at www2.mmm.ucar.edu/wrf/users/docs/arw_v3.pdf.] 
Stensrud, D. J., 2007: Parameterization Schemes: Keys to Understanding Numerical Weather Prediction Models. Cambridge University Press, 480 pp.

Stull, R. B., 1988: An Introduction to Boundary Layer Meteorology. Kluwer Academic Publishers, 666 pp. , 1991: Static stability-an update. Bull. Am. Meteor. Soc., 72, 1521-1529, CrossRef. , 2000: Meteorology for Scientists and Engineers. Brooks/Cole, 502 pp.

Tennekes, H., 1973: A model for the dynamics of the inversion above a convective boundary layer. J. Atmos. Sci., 30, 558-567, CrossRef.

, and A. G. M. Driedonks, 1981: Basic entrainment equations for the atmospheric boundary layer. BoundLay Meteorol., 20, 515-531, CrossRef.

Thompson, G, R. M. Rasmussen, and K. Manning, 2004: Explicit forecasts of winter precipitation using an improved bulk microphysics scheme. Part I: Description of sensitivity analysis. Mon. Wea. Rev., 132, 519-542, CrossRef.

, P. R. Field, W. D. Hall, R. M. Rasmussen, 2006: A new bulk microphysics parameterization for WRF and MM5. Seventh Weather and Research Forecasting Workshop, NCAR, Boulder, CO.
Turner, D. B., 1964: A diffusion model for an urban area. $J$. Appl. Meteor., 3, 83-91, CrossRef.

Vaughan, M. A., S. A. Young, D. M. Winker, K. A. Powell, A. H. Omar, Z. Liu, Y. Hu, and C. A. Hostetler, 2004: Fully automated analysis of space-based lidar data: an overview of the CALIPSO retrieval algorithms and data products. Proc. SPIE 5575, Laser Radar Techniques for Atmospheric Sensing, 16, CrossRef.

Vogelezang, D. H. P., and A. A. M. Holtslag, 1996: Evaluation and model impacts of alternative boundarylayer height formulations. Bound-Lay Meteorol., 81, 245-269, CrossRef.

Wu, Y., C.-M. Gan, L. Cordero, B. Gross, F. Moshary, and S. Ahmed, 2010: PBL-height derivation from the CALIOP/CALIPSO and comparing with the radiosonde and ground-based lidar measurements. Proc. SPIE 7832, Lidar Technologies, Techniques, and Measurements for Atmospheric Remote Sensing VI, 78320C, CrossRef.

Yamada, T., and S. Berman, 1979: A critical evaluation of a simple mixed-layer model with penetrative convection. J. Appl. Meteor., 18, 781-786, CrossRef.

Zilitinkevich, S., and A. Baklanov, 2002: Calculation of the height of the stable boundary layer in practical applications. Bound-Lay Meteorol., 105, 389-409, CrossRef. 